\title{
The Effect of National Culture Differences on Perceived Organisational Support: Examining the Case of India and the United Kingdom
}

\author{
NIMISHA BHATNAGAR \\ London School of Economics and Political Science, UK
}

\begin{abstract}
Due to increasing globalisation and expansion of multiculturalism, national culture has become an important area of research. There have been numerous cross-cultural studies exploring national culture differences between countries, and their consequent impact on functioning within a country. There has been considerable evidence that national culture affects the organisational practices. Perceived Organisational Support (POS) has been highly recognised as affecting behaviours that are beneficial for an organisation. However, none of the studies have attempted to figure out whether a relationship exists between national culture and POS.
\end{abstract}

The aim of this research is to explore national culture differences between India and the UK, and discover the effect on POS. India and the UK were the chosen sample groups due to their variation in recognised cultural perspectives, although they have a shared colonial history. The study consisted of 110 participants (49 and 61 from the UK and India respectively). These participants were aged between 20-60 years and all were working for an organisation. A quantitative approach was taken, where an electronic survey was distributed to be filled out by the sample population. Statistical methods including t-test and multiple regression were performed for the analysis.

The results indicated that there is no statistical difference between the national culture of India and the UK, and that subsequently has no effect on POS. The new cultural findings obtained with respect to India and the UK will direct further research in this field.

\section{Keywords}

national culture, perceived organisational support, cross-cultural, globalisation, multiculturalism

\section{Introduction}

As the world moves towards a more competitive business place, employment relationships are becoming more critical and have received considerable attention. Perceived Organisational Support (POS), an organisation supportive practice, is a psychological belief gathered by employees about their organisations in context of whether the organisations care about their contributions at work and general wellbeing (Eisenberger et al 1986). Fairness, supervisor support, and rewards and job conditions within an organisation act as predecessors for POS.

POS in many studies has been associated with synergising the wellbeing of employees with the growth of the organisations. It has been found to influence productivity, reduce absenteeism, increase turnover and general 
reduction in operating costs (Rhoades and Eisenberger 2002). In a nutshell, this is highly beneficial for accomplishment of organisational goals.

Hofstede defines culture as "the collective programming of the mind which distinguishes the members of one group or category of people from another" (1991, p.5). This further introduces the concept of National Culture, which can be described as a confluence of cultural and social norms, attributes and ethos shared by citizens of a nation within its boundaries that differ from the cultural values of another nation.

Several studies have documented that management and HR practices can be highly productive when they become aligned to the values and responses, specific to a National Culture. Thus, it is imperative that different national cultures have to be supported with a variation in the practices and social rules and regulations, applicable to that in particular (Newman and Nollen 1996). Management practices reinforced via national culture are instrumental in predicting employee behaviour and performance (Wright and Mischel 1987). Congruent management practices with national culture support concentration and managing of expectations within the workplace (Newman and Nollen 1996). For this reason, national culture has a huge impact on the working population of a country.

This relationship between national culture and management practices helps to identify another subject for wider debate: whether differences in national culture impact POS differently?

The study aimed to derive the cultural differences between India and the UK and also investigate the relationship between national culture and POS for both the countries.

\section{History and Genesis of National Culture}

The term 'Culture' carries us back to history in the 1800s; however, it is still a very difficult term to define concisely. The word 'Culture' has originated from two words 'cultus' and 'colere', meaning 'to care' and 'till the ground' respectively.

National culture can be described as a loose summation of espoused cultural values and beliefs shared by a country. Hofstede (1980) defined national culture as "collective mental programming of the people of any particular nationality." This programming developed within the society as a combination of attitudes and resultant behavior of citizens of that country, which sustains their priorities.

He introduced the dimensions of culture through empirical research involving 116000 surveys conducted across from 50 countries and 3 
continental regions. This data had been sourced from a large multinational company IBM (Hermes). Through this study, he discovered four bipolar dimensions of national culture: - Power Distance, Individualism, Masculinity, and Uncertainty Avoidance.

Later in 1991, Hofstede introduced a fifth dimension called 'Long-Term versus Short-Term Orientation' originally called Confucian dynamism (Hofstede and Bond 1988; Hofstede 2001).

Furthermore, the research by Michael Minkov on the World Values Survey data added new perspective to the fifth dimension and also discovered a sixth dimension called the 'Indulgence versus Restraint' (Hofstede and Minkov 2010).

\section{- Power Distance (PDI)}

The degree to which individuals/ members, who are less powerful in a society recognise that power is allocated disproportionately and accept it as being normal, is known as Power Distance.

\section{- Individualism - Collectivism (IND)}

This dimension indicates the relationship between individuals in a society. Individualism in a society stands for weak relationships within individuals. The individualistic society is accountable only for oneself, their interests and one's close immediate family. Collectivism in a society is identified by strong and integrated relations that individuals maintain with others. People in this kind of society belong to many in-groups. Such cultures have strong community support. Individuals attain loyalty from these in-groups (clan, work team, organisation, community, country) in exchange for support and protection (VSM Manual 2013).

\section{- Masculinity- Femininity (MAS)}

This dimension explains the extent to which masculine traits are preferred over feminine traits in a society. It foresees how society places emphasis on the issue of gender and their specific roles. A masculine society is one in which social gender roles are evidently distinct whereas in a feminine society the roles overlap. Masculine traits are identified at this juncture as being assertive, tough, successful and a performer. Alternatively, feminine traits are acknowledged to be modest, demure and relationship oriented.

\section{- Uncertainty Avoidance (UAI)}

Uncertainty Avoidance explains the degree to which individuals in a society feel threatened with ambiguity or unstructured situations. It explains the way 
individuals perceive control over events and how they manage the future. Low UAI in countries identifies a need for clear structure and order. Rules and guidelines in such societies help overcome difficulties faced via uncertainties.

\section{- Long Term Orientation- Short Term orientation (LTO)}

This dimension glances at a country's time and future orientation. Long-term orientation within a society promotes virtues, taking into account future rewards. Patience, perseverance and adapting to changes for a larger good of the future are some characteristics underlying in such societies [VSM 2013].

Short-term orientation recognises the past and the present. Features like national pride, respecting traditions and fulfilling social obligations is categorised as highly important in such societies.

\section{- Indulgence-Restraint (IVR)}

An indulgent society allows free gratification of desires and feelings contextually related to enjoying friends and life. Contrary to this, a restraint society controls similar gratification due to which individuals feel that they enjoy life less than others.

\section{National culture of India and the United Kingdom}

The two countries share common ground in history as a result of British colonisation in India. Yet, these countries encompass absolutely polarising cultural attributes and beliefs.

The United Kingdom sustains a westernised cultural approach. The country supports a culture wherein community relationships and personal friendships do not take priority over professional engagements. Most of the time, they would appear to be straightforward, clear and concise towards their approaches and thoughts (Trompenaars and Turner 1997). They prefer representing themselves as individuals rather than being considered as a part of an in-group. They also consider themselves to be the sole decision makers (which may not necessitate consulting seniors in decision-making) and are recognised as achievement oriented (Kowol and Szumieł, n.d.).

On the contrary, decision making in India has traditionally been a collective exercise, where familial relationships endure and are necessary, even in business relationships. The age old tradition of the caste system in India further contributes to this loyalty within familial bonds, thus emphasising established hierarchical relationships. A person is deemed to be affiliated to a specific state, region, city, family, career path, or religion, rather than the role of a mere individual. Indians have always been conscious of social order 
and their status relative to other people, be they family, friends or strangers. All relationships involve hierarchies. The patriarch, usually the senior most male member of the family at large, is considered the leader of the family. The reporting officer in the office may not be only the proverbial boss, but also the bearer of the ultimate responsibility in business in addition to the well-being of his pack of sub-ordinates. Every relationship dwells upon a clear-cut hierarchy that must be observed for maintenance of the social order. This group orientation emanates from the close, personal ties that Indians maintain with their family, including the extended family. This helps to create a myriad of inter-relationships, rules and structures and along with these mutual obligations, a deep rooted trust sets in among the relatives.

However, increased globalisation, fast urbanisation and general economic development since the ushering in of liberation reforms from the nineties, has resulted in a greater number of nuclear families in cities. This has tended to create a cultural shift towards individualism and personal achievement. Besides, the increased entry of global firms across India due to cheap labour costs and a large domestic market has also impacted both culture and employee expectations (Jacobsen 2014). Nevertheless, the reality and understanding about Indian culture still remains as complex and understated as it was hundreds of years ago.

\section{National culture in the present scenario}

In the present-day scenario, individuals have started feeling affiliated to various cultural attributes due to the growing globalisation and technological developments. Social and professional networking platforms actively encourage individuals to gain knowledge about the world. This also provides a route for individuals to possess a multiple identity belonging to various sub-cultures. Inter-cultural communication, thus, is crossing boundaries and merging features of various cultures, raising a transcultural world (Welsch 2009, cited in Witchalls 2012). Soderberg (2002) argues that national culture is now obsolete for managing the dilemma within institutions undertaking a transnational approach.

Individuals interpret situations and contexts differently, due to social representations which may be long shared within the nation (Jankowicz 1994). This schema is dependent upon the nation's history, experiences and current state. Although industrialisation and modernity is bringing individuals together, yet it is their social and cultural systems, which bind meaning to new information gathered through various sources (Witchalls 2012). 
Migration is another crucial element in globalisation and research suggests that it has highly added to the development of "colonialism, industrialisation and nation-building" (Castles 2002).

Understanding migration has become highly important, as it facilitates a deeper analysis about the social and cultural shift, paving way for future societal growth and welfare measures.

Currently migration poses a lot of differences, leading way towards resultant globalisation (Castles 2002):

- Migration adds to diversity: bringing different social and cultural backgrounds together.

- Migration brings in development of transport, knowledge and technology amplifying circulatory migration

- A higher number of migrants develop transnational feelings orienting their lives towards two societies and cultural values.

Migration to the UK within the last two decades has become a key matter for research and evaluation. Since 1998, the number of immigrants into the UK has exceeded emigrants from the country by as many as 100,000 persons a year. In 2014, individuals migrating to the UK constituted 13\% British nationals, 42\% EU migrants, and 45\% non-EU migrants (Hawkins 2016). The statistics portray the call for diversity in the UK, gathering different cultural views together.

Records from the British Home Office (cited in Khadria 2006) report that 687,000 Indians were admitted to the UK out of 11,800,000 non EEA in the year 2005. This rate has drastically increased, about $12 \%$, from 2004 .

\section{Perceived Organisational Support}

Social exchange theories highlight that individuals, when involved into any relationship with other people, attempt to maximise their own benefits. In addition, these theories understand the importance of employee motivation and its liaison that fosters the accomplishment of organisational goals (Aselage and Eisenberger 2003).

Organisational Support Theory (OST), a contemporary social exchange theory, assumes that employees develop beliefs as to how their organisation cares for and values their contribution. They also try to relate the organisation's willingness to appraise an increased work effort with their own well-being, so as to fulfill and nurture their socio-emotional needs. (Orpen 1994). 
This belief was termed "Perceived Organisational Support (POS)" in 1986 by Eisenberger, Huntington, Hutchinson, and Sowa. These feelings generated within employees as they allocate human characteristics to their organisations, which creates expectations that help will be assured whenever required by the organisation (Eisenberger et al 1986).

The organisational norms, policies and culture help individuals identify their role behaviour that also captures employees' personification with the organisation overlooking its individuality. This also takes place due to the moral, legal and financial dependency of an employee over the organisation (Levinson 1965).

\section{National Culture and Organisations: Understanding the differences within nations and the implications for organisations}

The previous American Management theory emphasised that 'one size fits all'. This made us believe that organisational practices and beliefs should be absolutely the same across different countries: be it the US, the UK, China or India. However, a new perspective has now taken over, showing that organisational practices must differ across nations (Newman and Nollen 1996).

Different countries may bind and allude to a wide plethora of various cultural practices, rules, regulations, norms and taboos. Many organisations today are running their businesses across multi-national borders and in differing crosscultural identities. Underestimating the importance and consideration of local social and cultural values may lead to unexpected hassles, mar interpersonal relationships, and ultimately lower business performance (Ghemawat and Reiche 2011). Evidence in various research also suggests that different countries adopt varied models for their business structure, legislative requirements, employment relationships, HRM competence and decision making to sustain their human assets (Schuler and Rogovsky 1998).

\section{Methodology}

Study gathered data from a total of 110 participants, out of which 61 were respondents from India and the rest 49 belonged to the UK. The inclusion criteria of the participants were as follows: they were aged between 20 and 60 years and were working for an organisation in these respective countries.

The research answered the following questions:

1. Does national culture differ between India and the UK?

2. Does Perceived Organisational Support differ in India and the UK?

3. Does national culture have an impact on POS? 
4. What are the other useful predictors explaining the relationship between national culture and POS?

The analysis was twofold: Firstly, the data was tested for any significant difference between the national culture and POS of India and the UK. Secondly, statistical techniques were applied to find out if there was significant impact of national culture on POS with control variables as age and tenure. Multiple Regression was performed to uncover this relationship.

\section{Discussion and Conclusion}

The results posed non-significant results with respect to the relationship between national culture and POS. However, it showed some interesting facts that could suggest a new understanding about the cultural aspects of both India and the UK.

Four new findings were considered of great importance which were: India scored low on power distance index, the UK scored as a collectivistic country, the UK is derived as a feminine country and India is also scored as an indulgent nation. These findings contradict the previous knowledge and literature as investigated (Hofstede et al 2010; Trompenaars and Turner 1997; Kowol and Szumieł, n.d.) Additionally, similar scores on the POS for India and the UK also indicate that similar support perceptions are derived within both countries.

These results question the basic understanding about the cultural values of these nations and raises questions to answer by what means these massive alterations have taken place.

The UK today exists as a diverse and multi-cultural country. Migration statistics (Hawkins 2016) state two major reasons for individuals to shift to the UK: work and formal education. The capital London consists of almost $37 \%$ individuals who were born outside the UK. Such a high concentration of diversity, coming from different cultural backgrounds, has extensively contributed to blurring boundaries across nations. This also explains the UK gathering collectivistic attributes within its boundaries, indicating that individuals within the UK now belong to a larger social network. Such a feeling of belonging to various sub-groups considerably affects an individual's actions and decisions in similar societies. Their adopted country now extends affiliation to their social networks like family, friends and workgroups.

Migration impacts globalisation and cultural changes. Other reasons like increased mobility due to cheap travel facilities and faster transportation modes, technological developments leading to reduction in communication barriers, also impact cultural flow. Such a wide diaspora in a working 
population also normalises national attributes, specific to a particular group, thus bringing in a feeling of trans-nationality (not belonging to one particular country) as an emerging theme (Castles 2002).

Globalisation is a dual process wherein both economic and cultural flow simultaneously takes place constituting flow of capital, goods, services, ideas, products and people. It also reduces the core features of a nation (Castles 2002). An intermingling of people from diverse faiths and nationalities, particularly in the form of migration, as has happened in the UK, has consequently conveyed alterations in the country's ideologies and beliefs.

The UK also tends to change its orientation to that a feminine country. Basic characteristics that distinguish a feminine society include maintaining worklife balance, individuals fostering equality, and caring for other members of the society.

This shift within the UK could be aligned with the elevated focus on worklife balance through government policies, being issued since 1997. Policies propagated, especially during the last two decades, have promoted work-life balance, focusing on maintaining high standards of life through rights like flexible employment patterns, extension of leave, child healthcare benefits, adoption of safe and best practices within the work environment (Lewis and Campbell 2007). The main focus of the policies has been to initiate equitable involvement and care for all members of the society. This appears to be a very strong reason for the UK tending to be a feminine country and establishing general support, uniform care and co-existential relationships as priorities within its culture.

Indian culture is also drastically evolving, bringing in a coalition of the traditional and modern views. M.N. Srinivas (1962) suggested that India was affected socially and culturally through the conquests of alien powers in varied times of its history. It is particularly the British period that caused a change within Indian traditional values. This influenced personal life, religious beliefs and social structure over many centuries in India. The resultant interactions with people from diverse backgrounds also brought about a cultural shift within the Indian population.

The role of foreign entities has often been considered to uphold a major role in changes associated with economic growth, innovation, and entrepreneurial behaviour (Gusfield 1967). A lower power distance in India suggests new entrepreneurial and cultural behaviour in the nation. This also shows that Indian nationals are no longer going to be satisfied with an unequal distribution of power. They believe in attaining autonomy and equitable distribution of resources: whether public or private. Workplaces 
now focus on greater involvement and team building, accessible and supportive seniors, and consensual decision-making by all members.

India has been previously recognised as sustaining high inequality of power and wealth within its society (Hofstede 2001; Muduli 2011). This was quite prevalent through social constructs like the caste system within Indian society and superior-subordinate relationships within the organisations. However, globalisation within the current era (specifically in the corporate sector) has led to incredible impacts on roles, lifestyles and relationships, particularly in countries like India (Gopalan and Stahl 1998).

We can relate this to the growing development of India as an after-effect of economic reforms initiated in the nineties. These radical changes in the business environment helped to modify the country's goals towards faster growth and eradication of poverty, which then became a priority for all successive governments, conveying a perceptible shift within the cultural attributes (Chen 1995). This finding also seems to support the study by Muduli (2011) who found inconsistency within the performance based rewards practice and national culture of India, as Hofstede's scores formerly indicated it to be a high power distance country. However, caution may be required to generalise these findings to other studies.

India has established various lifestyles within different groups of society. This division within the society expects specific groups to be the carriers of traditional values. Nations adapt to new cultural changes. However, this does not mean that old traditions were completely replaced by the newer ones (Gusfield 1967). Traditions and modernity can simultaneously co-exist and sustain one another under one roof. This further reinforces the viewpoint that Indians in general, are no longer going to be restrained by age old social norms. Change is inevitable and people will adopt the best practices that they see. Thus, India is recognised to be an Indulgent country through the index score obtained.

It is interesting to note that the young and the older generations may maintain substantially different views on any particular subject. With time, the younger generation has tended to be more independent in its outlook in terms of their opinion of life, family, friends, fun, sex and enjoyment. However, for the old, such drastic changes happening in Indian society may still be quite alien and challenging to accept. It may be mentioned that this study relied more on a higher percentage of younger generation (approximately 70\%) participating in the survey which may also be bringing forth such results for the country, which are more prevalent in western countries. 
With time, Indians are sustaining their cultural values and traditions and passing them on to their future generations. Yet they are also adopting and accepting best practices and views of the western society. Social media, 24hour television and accessible interactions across the globe could also bring legitimate understanding for this acceptance. "Interactions raise to fusion and mutual penetration" (Gusfield 1967), which explains that these interactions and increased knowledge about the world brings in these Western aspects of gratifying one's own needs and wants.

It is somewhat surprising that no difference was noted in POS between India and the UK. This showed that similar support systems are provided to the employees within organisations.

The link between national culture and POS was assumed on the basis of them being linked to organisational practices. Studies suggest that organisational practices have been adopted considering the national culture. However, the non-significant relationship found between POS and national culture raise dynamics that are worth mentioning. These are as follows:

- Our sample comprised of the general working population from India and UK, which shows that there was no synchronisation of factors like organisational culture and occupations of the employees. This further lends credence to the view that organisational culture could relatively be an important construct, while taking this relationship into account.

- Another possibility that may rise through context understanding is that POS seems to be a culture free organisational practice. A study undertaken in Egypt by Leat and El-Kot (2007) suggested that some HRM practices could be developed culture free. This study was based upon the Egyptian context; however, it raises an interesting fact due to the ever-growing diversity in culture. In addition, some practices are believed to be becoming culture free as employees tend to become a major asset for growth of their organisations. Thus, organisational support becomes an important contributor to an employee's ease at work and positive attitude towards their job. Thus, the presence of support is very much required within every culture and thus the organisation.

All these findings offer students and academics the chance to investigate evolution occurring in the global context. The study also makes way to further explore whether organisational culture should be positioned in the literature model developed. 


\section{Future Implications}

The findings from this research, however, are hard to generalise and pose several implications in the field of cultural and organisational research.

In prospects of cross-cultural research within India and the UK, this study provides novel insights, which can be administered on a larger sample to further refine the findings. The same can be generalised later in greater detail. Additionally, we might be able to develop greater insights by a logical, stratification of the sample through ethnic diversity within the country.

This study attempted to diagnose relationship between national culture and POS, raising a basic framework through literature relevant within organisational research. As per the author's knowledge, this was a completely new relationship, which was devised within organisational studies. The non-significant results suggest that the model still needs modification to develop this relationship further. The general population considered here also shows that a factor like organisational culture is necessary to investigate this relationship. Further research could be conducted taking into account these factors. This will further clarify whether the understanding of POS is a culturally devised practice or a culture free practice.

The current study also devises practical implications to organisations through its research question. POS benefits the organisation and its employees in many ways. The relationship formulated could bring greater insights within an organisational structure to manage their employees, their assets, in a more productive way, which brings in a further give and take relationship that fosters employee productivity and organisational development. 


\section{References}

Aselage, J., and Eisenberger, R. (2003). Perceived organizational support and psychological contracts: A theoretical integration. Journal of Organizational Behavior, 24(5), 491-509.

Castles, S. (2002). Migration and Community Formation under Conditions of Globalization. The International Migration Review, 36(4), 1143-1168. Retrieved from http:// www.jstor.org/stable/4149495

Chen, C.C. (1995). New Trends in Reward Allocation Preferences: A Sino-US Comparison. Academy of Management Journal, 38, 408-28

Eisenberger, R., Huntington, R., Hutchison, S. and Sowa, D. (1986). 'Perceived organizational support. Journal of Applied Psychology, 71, 500-507.

Ghemawat, P., and Reiche, S. (2011). National cultural differences and multinational business. Globalization Note Series, 1-18

Gopalan S and A Stahl. (1998). Application of American Management Theories and Practices to the Indian Business Environment: Understanding the impact of national culture. American Business Review, 16(2), 30-41

Gusfield, J. (1967). Tradition and Modernity: Misplaced Polarities in the Study of Social Change. American Journal of Sociology,72(4), 351-362. Retrieved from http:// www.jstor.org/stable/2775860

Hawkins, O. (2016). Migration Statistics. Briefing Paper Number SN06077. House of Commons Library, 1-28.

Hofstede, G. and Minkov, M., (2010). Hofstede's fifth dimension: New evidence from the World Values Survey. Journal of Cross-Cultural Psychology, 0022022110388567.

Hofstede, G. (1980), Culture's Consequences: International Differences in WorkRelated Values, Beverly Hills CA: Sage Publications.

Hofstede, G. (1983). National Cultures in Four Dimensions: A Research-Based Theory of Cultural Differences among Nations. International Studies of Management \& Organization, 13(1/2), 46-74. Retrieved from http://www.jstor.org/stable/40396953

Hofstede, G. (1991). Cultures and Organizations: Software of the Mind. London, UK: McGraw-Hill. 
Hofstede, G. (2001). Culture's Consequences: Comparing Values, Behaviors, Institutions and Organizations Across Nations, 2nd Edition, Thousand Oaks CA: Sage Publications.

Hofstede, G. (2011). Dimensionalizing Cultures: The Hofstede Model in Context. Online Readings in Psychology and Culture, 2(1). http://dx.doi.org/10.9707/2307-0919.1014

Hofstede, G., and Bond, M. H. (1988). The Confucius connection: From cultural roots to economic growth. Organizational dynamics, 16(4), 5-21.

Hofstede, G., Hofstede, G. J., Minkov, M., and Vinken, H. (2013). Values survey module 2013. URL: http://www. geerthofstede. nl/vsm2013.

Jacobsen, D. (2014). Recognizing across cultures: India. Globoforce. Retrieved from http://www.globoforce.com/gfblog/2014/recognizing-acrosscultures-india/

Jankowicz, A.D. (1994). The new Journey to Jerusalem: Mission and Meaning in the Managerial Crusade to Eastern Europe, Organization Studies 15(4): 479507.

Khadria, B. (2006). Migration between India and the UK. Public Policy Research, 13(3), 172-184. doi:10.1111/j.1744-540X.2006.00440.x

Kowol, A., and Szumieł, E. (n.d.). United Kingdom: communication, negotiations.

Leat, M. and El-Kot, G. (2007). HRM practices in Egypt: the influence of national context?.The International Journal of Human Resource Management, 18(1),147-158.

Levinson, H. (1965). Reciprocation: the relationship between man and organization. Administrative Science Quarterly, 9, 370-90.

Lewis, J., and Campbell, M. (2007). UK work/family balance policies and gender equality, 1997-2005. Social Politics: international studies in gender, state \& society, 14(1), 4-30.

Muduli, A. (2011). Performance based reward and National Culture: an empirical evidence from Indian culture. Synergy (0973-8819), 9(1).

Newman, K. L., and Nollen, S. D. (1996). Culture and congruence: The fit between management practices and national culture. Journal of international business studies, 27(4), 753-779. 
Orpen, C. (1994). The Effects of Exchange Ideology on the Relationship between Perceived Organizational Support and Job Performance. Journal of Social Psychology, 134 (3), 407-408.

Rhoades, L., and Eisenberger, R. (2002). Perceived organizational support: a review of the literature. Journal of applied psychology, 87(4), 698.

Schuler, R. S., and Rogovsky, N. (1998). Understanding compensation practice variations across firms: The impact of national culture. Journal of International Business Studies, 29(1), 159-177.

Soderberg, A-M. (2002) 'Rethinking Cross-Cultural Management in a Globalizing Business World', International Journal of Cross-Cultural Management (2)1: 103-121.

Srinivas, M. (1962). Changing Institutions and Values in Modern India. The Economic Weekly.

Trompenaars, F. \& Hampden-Turner, C. (1997), Riding the Waves of Culture: Understanding Cultural Diversity in Business, Second Edition, London \& Santa Rosa, Nicholas Brealey Publishing Limited

Witchalls, P. J. (2012). Is national culture still relevant?

Wright, J. D. and Mischel, W. (1987). A conditional approach to dispositional constructs: The local predictability of social behaviour. Journal of Personality and Social Psychology. 